\title{
STAGNATION REGION HEAT TRANSFER DUE TO A TURBULENT CIRCULAR IMPINGING AIR JETS
}

\author{
M. Attalla \\ Mechanical Engineering, Power and Energy Department \\ Faculty of Engineering, South Valley University - Qena - Egypt \\ Received 25 February 2013, accepted 14 May 2013
}

\begin{abstract}
The heat transfer characteristics in a stagnation region were investigated experimentally for a five circular free jets impinging into a heated flat plate. The local temperature distribution, on a thin flat plate was measured using thermal infrared camera. To get precise heat transfer data over the plate, fully developed straight pipe jets were used in this study. Mean jet Reynolds number varies from 1000 to 45000 and vertical distance jet-to-plate, H/D, from 2 to 6 , while the spacing jet-to-jet is, $\mathrm{S} / \mathrm{D}$, varies from 2 to 8 . A geometrical arrangement of one jet surrounded by four jets in-line array was tested. The results show that the stagnation point Nusselt number is correlated to a jet Reynolds number as $N u_{s t} \propto \mathrm{Re}^{0.61}$. The average Nusselt number is higher at a separation distance (H/D) of 2 for three cases of spacing distances, separation distance and $\overline{N u} \propto \operatorname{Re}^{0.68 *} \operatorname{Pr}^{0.33 *}(H / D)^{-0.103}$ Reynolds Number as .
\end{abstract}

Keyword: Stagnation point, Multiple Jets, Heat Transfer, Turbulent intensity.

\section{Introduction}

Jet impingement can be found in many engineering applications where high convection heat transfer rates are required. Applications include steel industry, drying of textiles, film, cooling of turbine blades and heating of glass products. Beside to above applications in cooling, impingement jets are also adopted in paper industry to enhance drying processes. Jet impingement has also been used for cooling of micro-electronic components $[1,2]$. The main objective of this study is to investigate the local and average heat transfer characteristics for a five circular impinging jets in the stagnation region in more details.

Single jet finds application mostly where highly localized heating or cooling is necessary. However, when large surface areas require cooling or heating, the multiple jet impingements are desirable. Characteristics of these are influenced basically by two types of interaction [3,4]. Firstly, the interaction between the adjacent jets can occur before impingement on the surface. This may happen when the distance between the jets is small and /or when the distance between the jet plane and the target plate plane is large [4]. Second, the wall jets formed by the adjacent jets collide on the target surface [4]. This interaction is very clear when multiple jets from perforated plate are used. The heat/mass transfer coefficient of multiple jets from free nozzle is more unified than the jets from perforated plate over the overall impingement surface [4, 5, and 6].

Many previous investigations have been carried out to understand the heat and mass transfer characteristics of arrays of impinging jets through experiments and numerical calculations $[7,8]$. They have been dealt with the effect of Reynolds number, jet to plate distance, spacing distance between jets, jets exit geometric effect, cross flow, etc. However, the stagnation region heat transfer has not been fully studied in spite of its practical significance.

\footnotetext{
* Corresponding author.

E-mail address: moha_attalla@yahoo.com
} 
For a circular jet impinging on a flat plate, it was concluded from early experimental results that, for the stagnation region, the maximum heat transfer happens at a jet to plate distance of about 6 times the jet diameter [9]. The radial heat transfer distributions show a second maximum at a jet to plate distance of H/D about 2 for particular Reynolds numbers. These are further confirmed by many other researchers, as reviewed by Lee and Lee [9].

Numerous studies are devoted to the investigation of heat transfer of arrays of impinging jets on different target surfaces. Attalla and Specht [4] studied the local and average Nusselt number distributions from nine jets $(3 * 3)$ using free nozzles. They showed that the average Nusselt number is higher where the spacing distance is 6-jet diameter. Huber and Viskanta [10] investigated the effect of cross flow on local and average Nusselt number values from nine orifices impinge into flat plate. They found that the maximum Nusselt number does not occur at stagnation point, but at secondary rings formed around the stagnation point. These secondary rings increase the spatially averaged heat transfer coefficient. Koopman and Sparrow [11] investigated local and average heat transfer from a row of impinging jets to a flat plate with $S / D=4$ to 10 and $R e=2500$ to 10000 . Hollworth and Berry [12] studied the heat transfer from arrays of impinging jets on a flat plate with large jet-to-jet spacing distance $(\mathrm{S} / \mathrm{D}=10-25)$. Goldstein and Timmer [13] used liquid crystal visualization technique to investigate the local heat transfer for a single circular impinging jet, three collinear jets, and seven jet array with one in the center. Goldstein and Behbahan [14] investigated the effect of jet-to-jet spacing and Reynolds number on the heat transfer from a staggered array of impinging circular jets to a flat plate, but the stagnation region is not discussed in this study.

There have been a few studies that investigate the effect of jet flow structures on the impinging jet heat transfer in stagnation region. Gardon and Akfirat [15] investigated the local heat transfer characteristics on impinging two dimensional and axisymmetric air jets in the central zone around the stagnation point. They also studied the effect of free stream turbulence on the heat transfer augmentation. Hoogendoorn [16] studied the effect of flow turbulence on the stagnation point heat transfer of impinging jets issuing from both a long straight pipe and smoothly convergent nozzle. Kataoka [17] investigated the role of artificially induced large scale eddies on the impinging jet heat transfer. Obat et al. [18] and Popiel and Boguslawski [6,5] found that the nozzle exit configuration is the most important factors affecting the radial and axial distributions of mean velocity. Aldabbagh and Mohamad [19] numerically investigated the effect of jet-to-jet spacing in flow and heat transfer for a five in-line array jets. The spacing between jets is varied from 2 to 20 times the width at a jet Reynolds number of 200. They found that, the horseshoe vortices formed at different position between the orifice and impinging plates are due to the interaction of two jets before they combine. Turbulence intensity, and kinetic energy, as well as turbulent shear stress, in the initial region of a turbulent jet issued from a long straight pipe.

In the present study, the local heat transfer characteristics in a stagnation region were investigated experimentally for four jets array with one jet in the center impinging normally to a heated flat plate. The impinging jets show very complicated flow phenomena inside the stagnation region, due to the interaction between the surrounding fluid exit from jets after and before impinging plate, consisting of a sudden change of flow direction toward the radial direction from stagnation point [9-11]. The objective of this study is to obtain a better understanding of the effect of the jet-to-jet spacing on heat transfer characteristics near the stagnation region. For the purpose of the study, long pipes (50

Journal of Engineering Sciences, Assiut University, Faculty of Engineering, Vol. 41, No. 4, July, 2013,E-mail address: jes@aun.edu.eg 
hydraulic diameter) with inner diameter of $\mathrm{D}=6 \mathrm{~mm}$ and IR system were used to achieve higher spatial resolution of the heat transfer coefficient $[4,20]$.

\section{Experimental apparatus}

The local heat transfer rates in the stagnation region were measured at dimensionless parameters jet-to-plate distance ratio $(\mathrm{H} / \mathrm{D}=2,4,6$, and 8$)$ and jet-to-jet spacing ratio (S/D $=2,4,6$, and 8) for five different jet Reynolds number ranging from 1,000 to 45,000. Figure 1 shows the experimental apparatus which consists of jets field, jet air flow metering system, metal sheet $(200 * 170 * 0.1 \mathrm{~mm})$, and the digital image processing system (IR Camera-thermo CAM® SC 3000). The metal sheet was heated electrically with direct current supply up to $400 \mathrm{~A}$ and $7 \mathrm{~V}$ and arranged horizontally to be cooled from the top side by the nozzles field. The surface temperature was measured by an infrared thermo camera from the bottom side. The temperature difference between both sheet sides was always lower than $0.065 \mathrm{~K}$ due to the small thickness of $0.1 \mathrm{~mm}$. Therefore, the temperature of both sides could be assumed to be equal $[4,21,22]$.

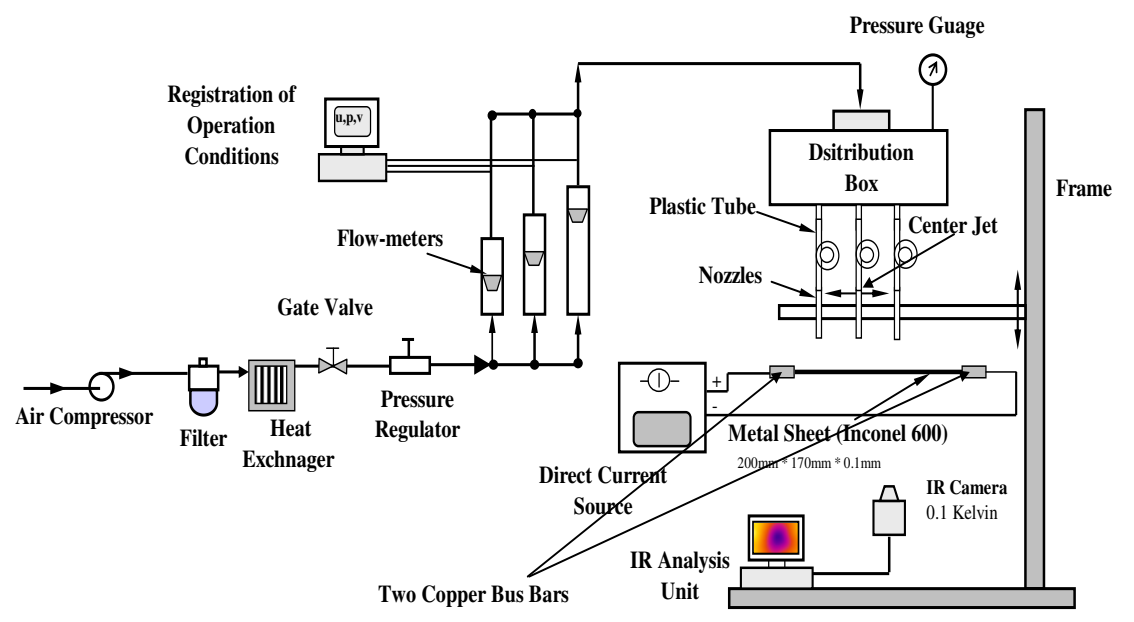

Fig. 1. Schematic view of experimental apparatus

A schematic of the experimental apparatus is shown in Fig. 1. Compressed air (6 bar) flows through air filters, heat exchanger where it is cooled and dried and then though flowmeters to a distribution box. The heat exchanger was installed to adjust the air temperature so that the jet temperature issuing from the nozzle is maintained within $0.1{ }^{\circ} \mathrm{C}$. The air flow was controlled with valves, and a pressure regulator maintained a constant pressure upstream of the test-rig. Therefore a constant flow rate was obtained during each test. The flow rate was measured with a bank of flow meters. A perforated plate and cylinder are inserted in the distribution box to insure a uniform flow through each injection hole [4]. Five jets in a three rows, in-line arrays were used, as shown in Fig. 2. Each jet was formed by a free nozzle with an inner diameter $\mathrm{D}$ of $6 \mathrm{~mm}$ and a development flow length exceeding fifty diameters.

Journal of Engineering Sciences, Assiut University, Faculty of Engineering, Vol. 41, No. 4, July, 2013,E-mail address: jes@aun.edu.eg 


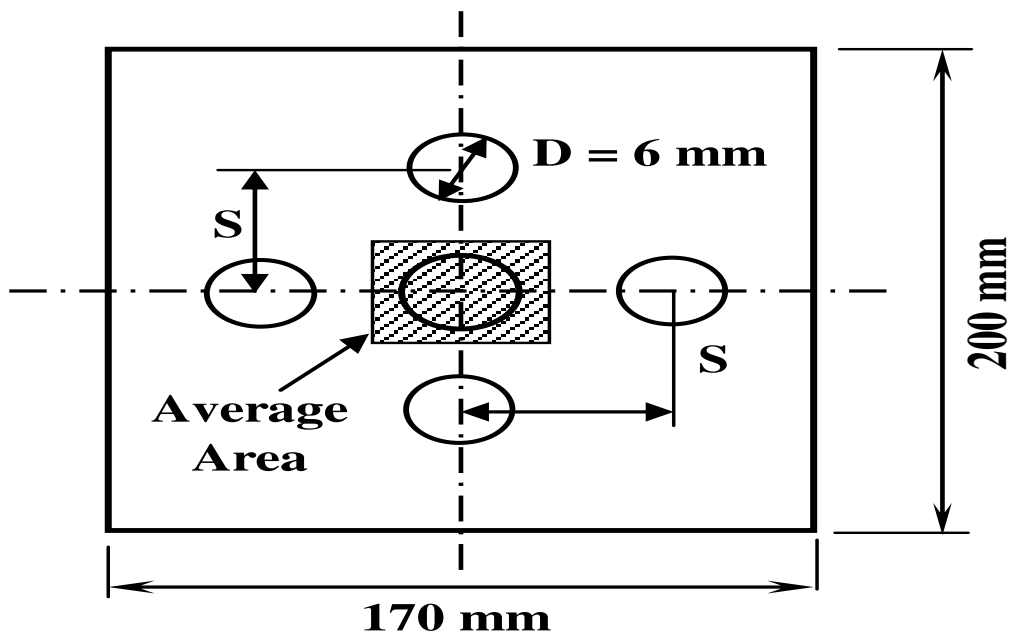

Fig. 2. In-line five jets arrays

\section{Heat transfer reduction and uncertainty analysis}

To determine the heat transfer coefficient for a position regarded on the test metal sheet, an energy balance was performed for the steady-state conditions,

$$
\mathrm{q}_{\mathrm{I}}=\mathrm{q}_{\alpha}+\mathrm{q}_{\mathrm{R}}+\mathrm{q}_{\alpha \mathrm{f}}+\mathrm{q}_{\mathrm{k}}
$$

The electrically generated power per unit surface area of sheet, $q_{I}$, is transferred to the environment by the forced convection, $q_{\alpha}$ by radiation, $\mathrm{q}_{\mathrm{R}}$ by free convection $\mathrm{q}_{\mathrm{k}}$ and by conduction heat transfer in the sheet. $q_{\alpha f}$ The electrical heat flux can be

$q_{I}$ calculated with the following equation:

$$
\mathrm{q}_{\mathrm{I}}=I^{2} \rho_{\mathrm{el}} \frac{1}{\mathrm{w}^{2} t}
$$

with I is the electric current, w, and t are the width and thickness respectively of the test metal sheet, and pel as specific electrical resistance of the metal, [4,20, 9].

Radiation, free convection and conduction were considered as heat losses. The radiation heat flux from both sides of the metal sheet is given by

$$
q_{R}=\left(\varepsilon_{1}+\varepsilon_{2}\right) \cdot \sigma \cdot\left(T_{O}^{4}-T_{a}^{4}\right)
$$

where $\varepsilon_{1}$ and $\varepsilon_{2}$ are the emissivities of top and bottom metal sheet surfaces respectively. [4,21].

The heat was conducted into the metal sheet plane from outer region of the sheet to its center. This is due to the radial temperature distribution with the minimum temperature at the center of the jet. Conduction net heat transfer rate in radial direction for an element per unit surface area $\mathrm{q}_{\mathrm{k}}$ can be calculated using Fourier's differential equation for cylindrical coordinates, Eq. 4

Journal of Engineering Sciences, Assiut University, Faculty of Engineering, Vol. 41, No. 4, July, 2013,E-mail address: jes@aun.edu.eg 


$$
\mathrm{q}_{\mathrm{k}}=-\mathrm{t} . \mathrm{k}_{\mathrm{m}} \cdot \frac{1}{\mathrm{R}} \cdot \frac{\partial}{\partial \mathrm{R}}\left(\mathrm{R} . \partial \mathrm{T}_{\mathrm{o}} / \partial \mathrm{R}\right)
$$

where $\mathrm{km}$ is the thermal conductivity of metal sheet. For all experimental conditions, this conduction heat flux was estimated lower than $2 \%$ of the total input heat flux $[4,20]$.

The free convection heat flux from the lower surface of the metal sheet is calculated using the following equation:

$$
q_{\alpha f}=\alpha_{f}\left(T_{o}-T_{a}\right)
$$

The heat transfer coefficient $\alpha_{\mathrm{f}}$ depends on the mean temperature of the sheet and on its size. Its value was in the range 4-7 W/m2 K [4,21].

The total heat losses amounted up to $10 \%$ of the electrical heat flux for laminar flow. For turbulent flows, the heat losses were reduced to value down to $2 \%[4,21]$.

The heat flux by forced convection was caused by the flow impingement against metal sheet and was calculated by [4];

$$
\mathrm{q}_{\alpha}=\alpha\left(\mathrm{T}_{\mathrm{o}}-\mathrm{T}_{\mathrm{ad}}\right)
$$

where $\alpha$ is the forced convective heat transfer coefficient and Tad is the adiabatic impinged wall temperature. In case when the exit velocities lower than $104 \mathrm{~m} / \mathrm{s}$, the difference between the adiabatic wall temperature and exit jet temperature is less than 2.5 $\mathrm{K}$ [4]. Thus, the adiabatic wall temperate in the last equations can be replaced by exit jet temperature $\mathrm{Tj}$.

The local heat transfer coefficient $\alpha$ is presented in dimensionless form by local Nusselt number

$$
\mathrm{Nu}=\alpha \cdot \mathrm{D} / \mathrm{k}
$$

The results can be expressed in terms of the dimensionless counterpart of the jet exit velocity $\mathrm{V}$, the Reynolds number

$$
\mathrm{Re}=\mathrm{V} \cdot \mathrm{D} / \mathrm{v}
$$

The local Nusselt number distribution can be averaged to obtain an average Nusselt number. The average Nusselt number is defined as

$$
\overline{\mathrm{NU}}=\frac{\bar{\alpha} \mathrm{D}}{\mathrm{k}}=\frac{\mathrm{D}}{\mathrm{k}} \int_{\mathrm{A}} \alpha \frac{\left(\mathrm{T}_{\mathrm{o}}-\mathrm{T}_{\mathrm{ad}}\right) \cdot \mathrm{dA}}{\mathrm{A} \overline{\Delta T}}
$$

also defined as

where the average temperature difference $\overline{\Delta T}$ is

$$
\overline{\Delta \mathrm{T}}=\overline{\left(\mathrm{T}_{\mathrm{o}}-\mathrm{T}_{\mathrm{ad}}\right)}=\int_{\mathrm{A}} \frac{\left(\mathrm{T}_{\mathrm{o}}-\mathrm{T}_{\mathrm{ad}}\right) \cdot \mathrm{dA}}{\mathrm{A}}
$$

It is noted that the mean values of both $\overline{\mathrm{Nu}}$ and $\overline{\Delta \mathrm{T}}$ are expected to depend on the area A over which the quantities are to be averaged, where A is unit cell area around each temperature measurement at the metal sheet as shown in Fig. 2 [4, 9, 21].

The Uncertainty of the measured local Nusselt number has been evaluated for all experimental arrangements and the procedure used the followed methods suggested by Kline and McClintoock [23], with a 96\% confidence level. The total uncertainty in the Nusselt number measured ranged from $1.5 \%$ to $4.5 \%$. The non-uniformity factor of the coating was the largest contributer to the total uncertainty, and its uncertainty ranged from $1.2 \%$ to $2.9 \%$ [4]. Another important source of uncertainty was the wall temperature To of

Journal of Engineering Sciences, Assiut University, Faculty of Engineering, Vol. 41, No. 4, July, 2013,E-mail address: jes@aun.edu.eg 
which the uncertainty ranged from $0.75 \%$ of to $1.45 \%$. The uncertainty in the Reynolds number was estimated to be in the range $1.25 \%-2.15 \%$.

\section{Results and discussion}

\subsection{Stagnation point nusselt number}

The Surface temperature field of five jets in-line array for maximum Reynolds number, $(\operatorname{Re}$ $=45000$ ) and spacing distance, $\mathrm{S} / \mathrm{D}=4$ at a separation distance $\mathrm{H} / \mathrm{D}=4$ is shown in Fig. 3. It is observed that the temperature field is clearly symmetric for all neighbor jets. Therefore, all neighbor jets have the same effect on the center jet. Consequently, in the present study, the effect of the second stagnation point Nusselt number, $\mathrm{Nu}_{\mathrm{st} 2}$, on center jet can be calculated from any neighbor jet. This effect will be shown in more details in Fig. 4a-c.
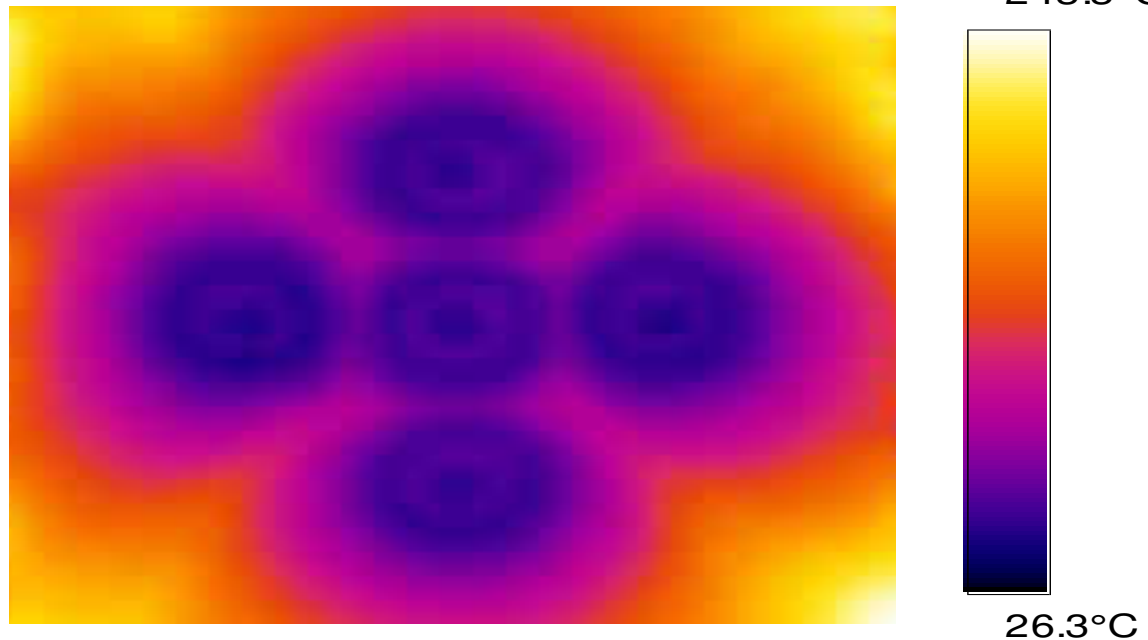

Fig. 3. IR-thermograph picture at $\mathrm{Re}=45000$, and $\mathrm{S} / \mathrm{D}=4$

The variations of the first stagnation point Nusselt number, Nust1, at center jet and the second stagnation point Nusselt number, Nust2, from neighbour jet, with jet Remolds number $(\mathrm{Re})$ are shown in Fig. 4a-c for separation distances, $2 \leq \mathrm{H} / \mathrm{D} \leq 8$, and spacing distances $\mathrm{S} / \mathrm{D}=$ 2,4 , and 8 . In the case of $S / D=2$, the stagnation point Nusselt number for two cases first and second (Nust 1 and Nust2) is varied according to Nust $\propto$ Re0.52, which agrees closely with the laminar boundary flow case [9]. In addition, the second stagnation point Nusselt number is approximately $14.7 \%$ higher than the first stagnation point Nusselt number. This is due to the strong interaction between flows from jets. In the cases of spacing distance ratios $S / D=4$, and 6 , the second stagnation point Nusselt numbers is close to the first stagnation point Nusselt number, and the Nusselt number is nearly proportional to Re 0.61 for the two cases.

Journal of Engineering Sciences, Assiut University, Faculty of Engineering, Vol. 41, No. 4, July, 2013,E-mail address: jes@aun.edu.eg 


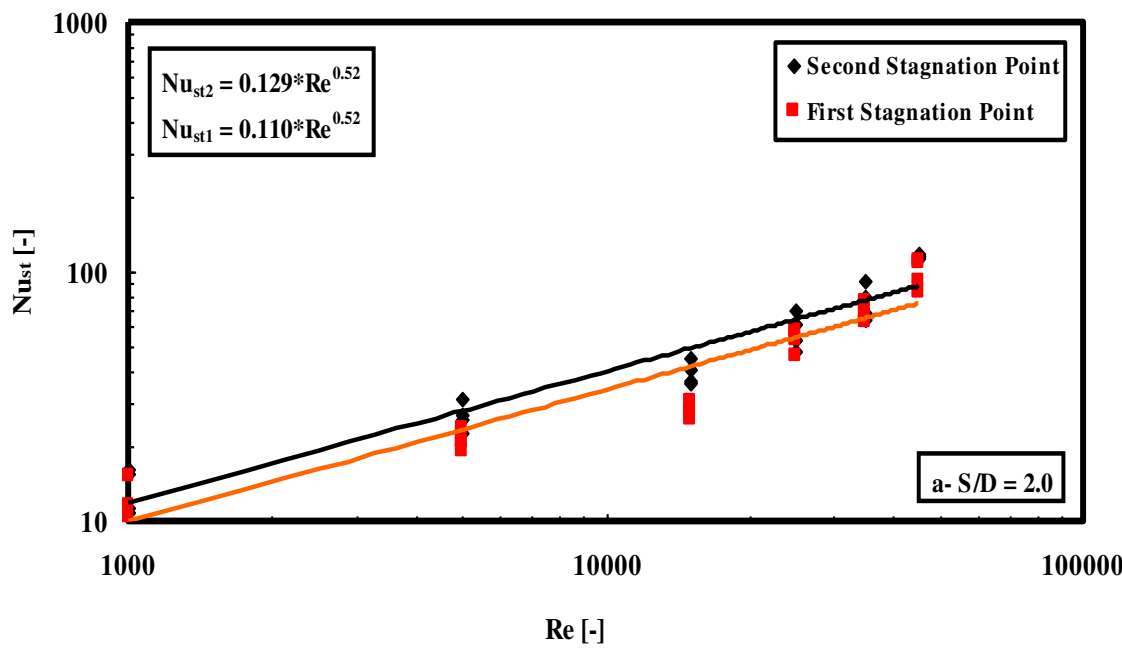

Fig. 4a. Stagnation Nusselt number variation with jet Reynolds number.

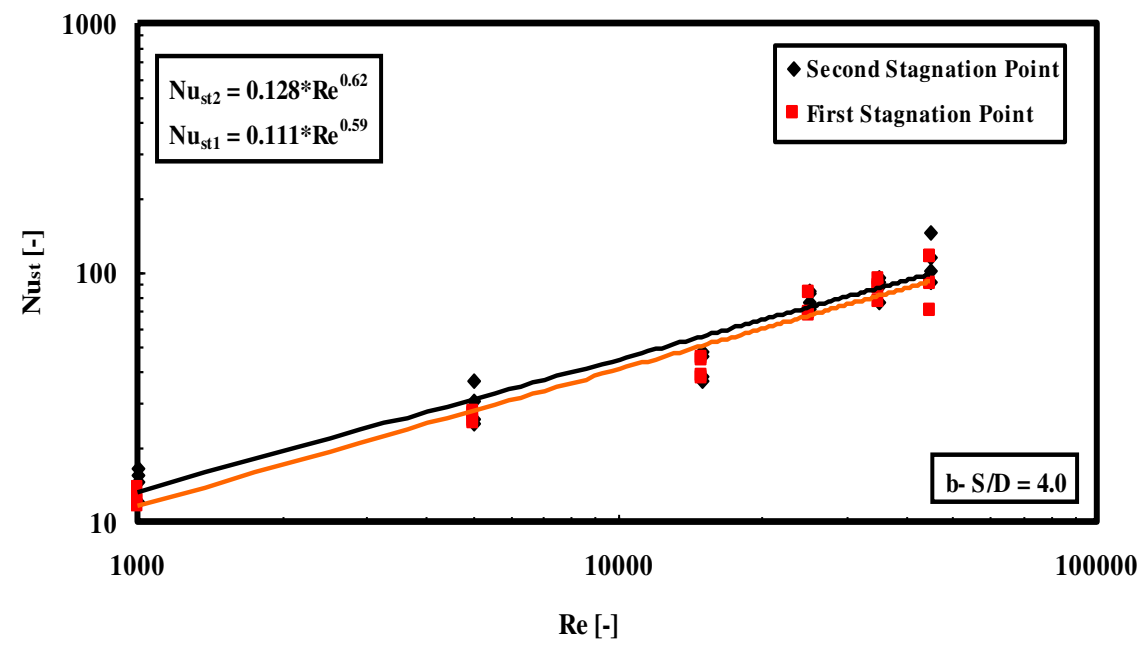

Fig. 4b. Stagnation Nusselt number variation with jet Reynolds number.

In case of an increase in the spacing distances, $S / D=8$, the second stagnation point Nusselt number is nearly the same as the first stagnation point Nusselt number and dependence becomes stronger (Nust $\propto \operatorname{Re} 0.60$ ) as shown in Fig. 4c. The result is due to the distance increase between jets, so that the interaction between flows is weak $[4,21]$. 


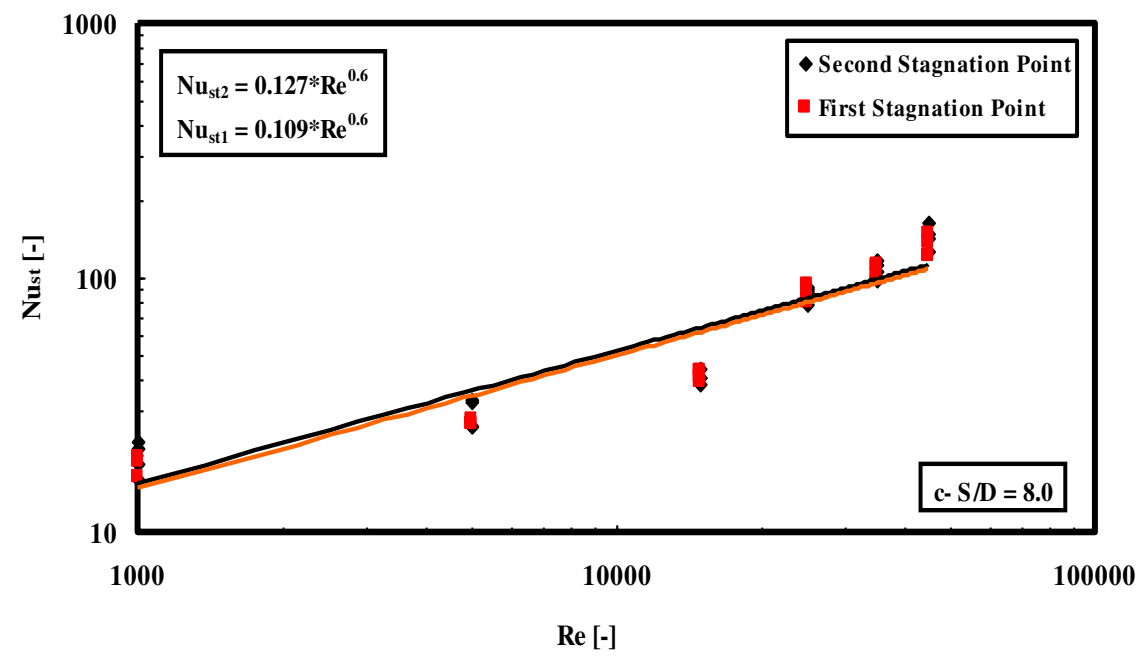

Fig. 4c. Stagnation Nusselt number variation with jet Reynolds number.

\subsection{Local nusselt number}

The radial distribution of local Nusselt number of five jets is presented in Figs. 5-8, for five Reynolds number values and four nozzle-to-plate distances ratios $(\mathrm{H} / \mathrm{D}=2,4$ and 8), and the spacing distance ratio varies from 2 to 8 . The profiles of the local Nusselt number are similar to those of the multiple array nozzles [4,21]. In case of the small spacing distances $\mathrm{S} / \mathrm{D}=2$, and due to shear layer expansion, the interference between adjacent jets occurs before impinging. This interaction may weaken the jet strength and eventually degrade the heat transfer of jet array, [24]. So, the local Nusselt number profiles decrease from the first stagnation point to the middle distance between jets $(\mathrm{R} / \mathrm{D}=1)$, and then increases to the second stagnation point at $\mathrm{R} / \mathrm{D}=2$, Fig. $5 \mathrm{a}$.

In this case, no second peak occurs for all separation distances $H / D$ in region of $0 \leq R / D$ $\leq 2$. Since the flow, which is coming out of the neighboring jets is free, the second peak does not occur clearly. However, the tendency is maintained with nearly constant Nusselt number distribution at the transition zone $(2.8 \leq \mathrm{R} / \mathrm{D} \leq 3.2)$. This indicated that the nozzleto-plate $\mathrm{H} / \mathrm{D}=2$, and 4 can be a threshold for the second maximum to occur, Fig. 5a and Fig. 5b.

For $\mathrm{H} / \mathrm{D} \leq 8$, the local heat transfer (Nusselt number) decreases monotonically upon going outward along the impinged plate and does not show the second peak as shown in Fig. 5c. The turbulence intensity of the impinging free jet has a local maximum at the first and second stagnation points. In general the magnitude of local Nusselt number is reduced as the separation distance, $\mathrm{H} / \mathrm{D}$, increases. Previous studies showed that the maximum heat transfer occurs at the stagnation point for nozzle-to-plate separation distances greater than approximately four nozzle diameters [4, 9,19 and 21].

Journal of Engineering Sciences, Assiut University, Faculty of Engineering, Vol. 41, No. 4, July, 2013,E-mail address: jes@aun.edu.eg 


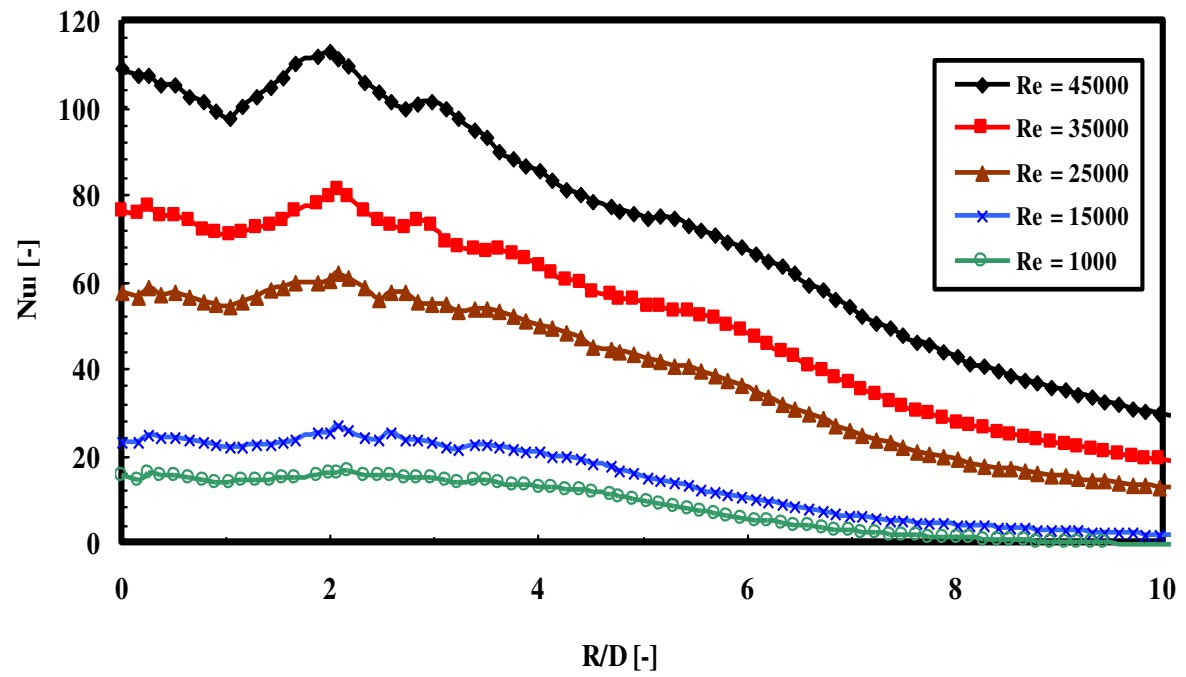

Fig. 5a. Radial variation of local Nusselt number at $S / D=2$, and $H / D=2.0$

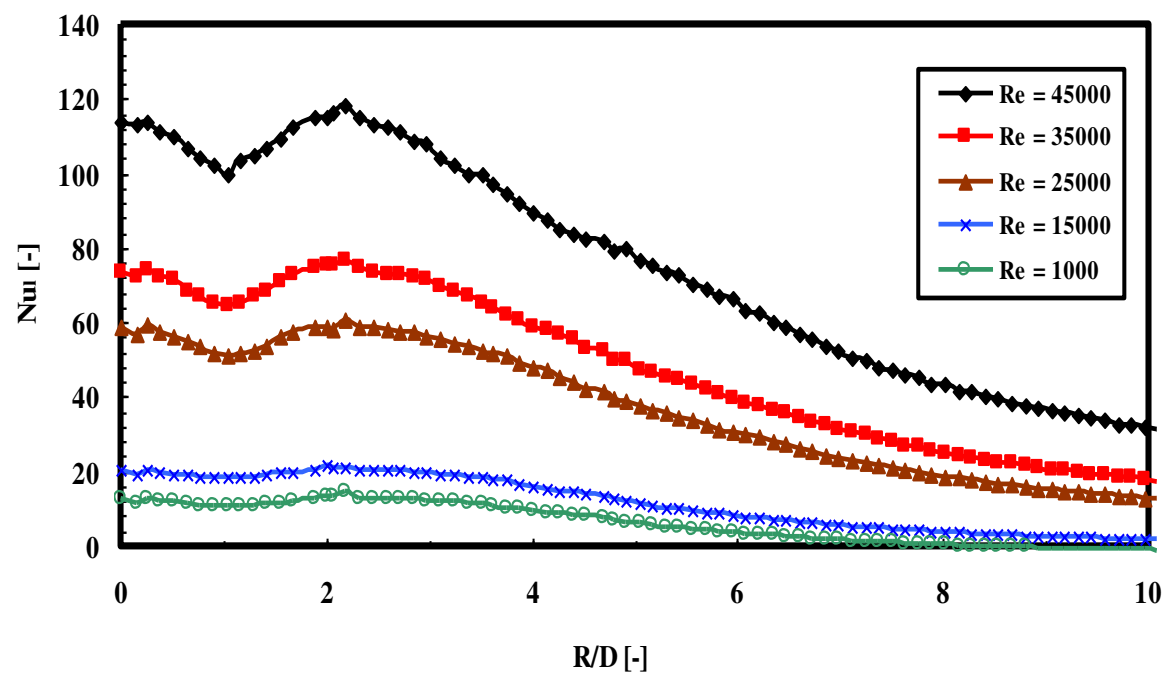

Fig. 5b. Radial variation of local Nusselt number at $S / D=2$, and $H / D=4.0$

Journal of Engineering Sciences, Assiut University, Faculty of Engineering, Vol. 41, No. 4, July, 2013,E-mail address: jes@aun.edu.eg 


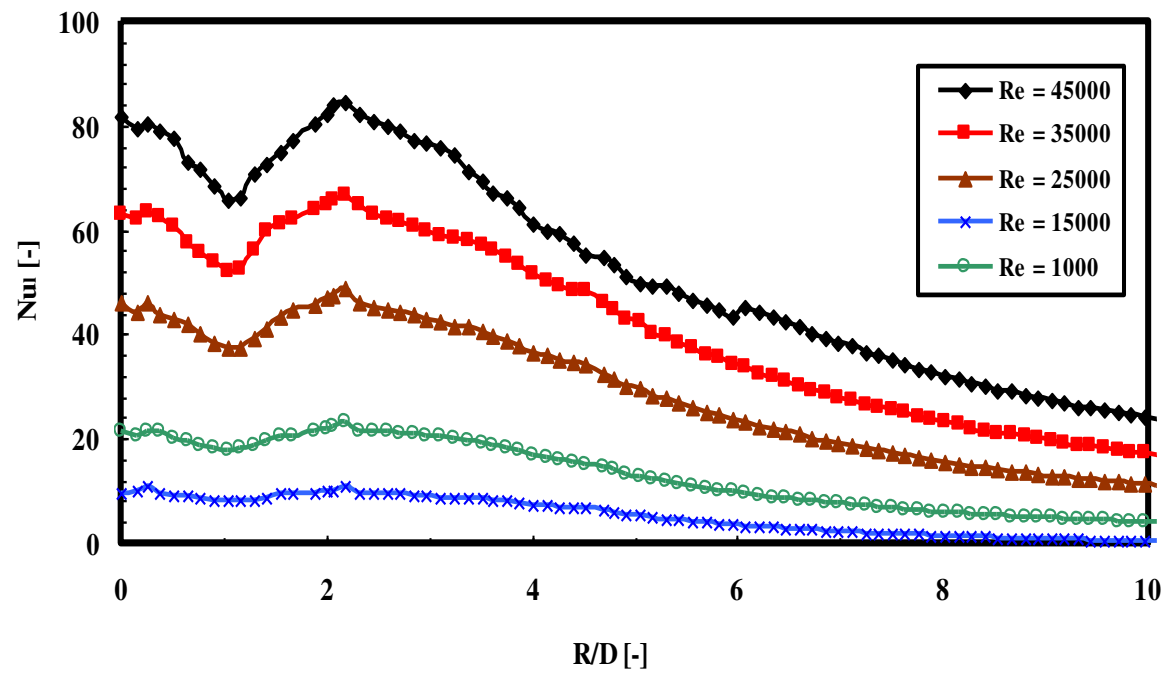

Fig. 5c. Radial variation of local Nusselt number at $S / D=2$, and $H / D=8.0$

Figure 6a-b shows the distribution of the local Nusselt number for $S / D=4$ and $H / D=2$, and 6 . In Fig. $6 a$ and $6 b$, the distances between jets increase, $(S / D=4)$ so that the effect of the interaction between flows out of the jets on heat transfer is reduced in wall jet region. The local Nusselt number distribution from the first stagnation point is decreased till $\mathrm{R} / \mathrm{D}=$ 0.4 and then increased at $\mathrm{R} / \mathrm{D}=0.5$ (first peak of stagnation region) for a separation distance $\mathrm{H} / \mathrm{D}=2$. In addition, the distribution of local Nusselt number from the second stagnation point $(R / D=4)$ is decreased to till the radial distance $R / D=6.25$. The local Nusselt number in nearly constant in redial distance region from $R / D=6.7$ to $R / D=7.7$ in case of $H / D=2$ (transition zone). In case of separation distance $H / D=6$, the value of Nusselt number is decreased from the first stagnation point at $R / D=0$ to $R / D=2$ because the effect of potential core is weak [9, 24, 25], as shown in Fig. 6b.

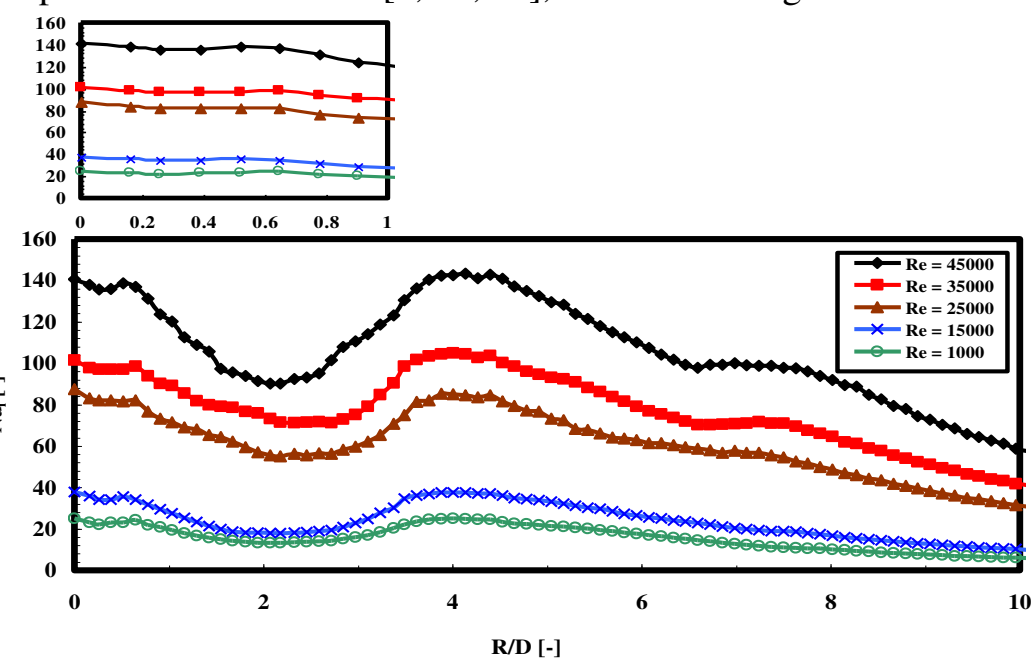

Fig. 6a. Radial variation of local Nusselt number at $S / D=4$, and $H / D=2.0$

Journal of Engineering Sciences, Assiut University, Faculty of Engineering, Vol. 41, No. 4, July, 2013,E-mail address: jes@aun.edu.eg 


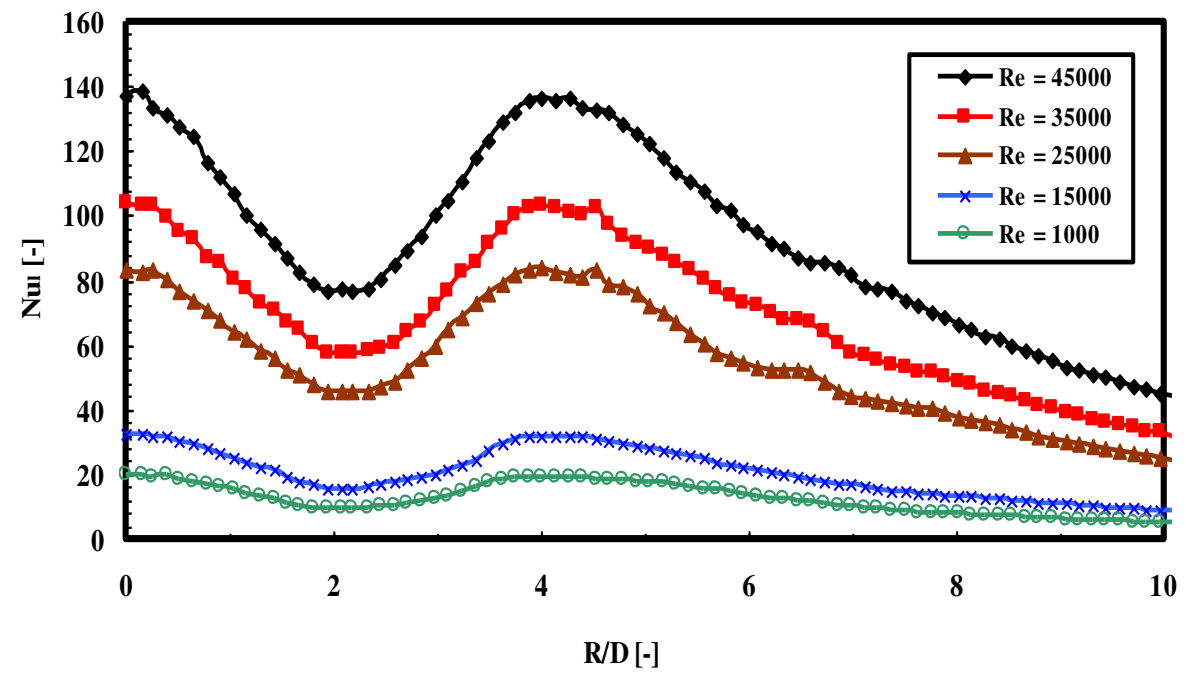

Fig. 6b. Radial variation of local Nusselt number at $S / D=4$, and $H / D=6.0$

The local Nusselt number distribution at spacing distances $S / D=6$, and 8 at different Reynolds number values $(\operatorname{Re}=45000,35000,25000,15000$, and 10000) and two different separation distance ratio $\mathrm{H} / \mathrm{D}=2$, and 4 , is presented in Fig.7a-b and Fig. 8. Concerning cases of $S / D=6$, and 8 , as the spacing distance is increased the strength of interaction is weak, so that the free fountain between jets will be formed [24]. Because the jets were formed from free jets, the fountain will be free between the jets, and the local Nusselt number distribution nearly becomes the same as of those in a single jet [24]. For separation distance of $H / D=2$, and the spacing distances $S / D=6$ and 8 , the second peak is formed from central jet at radial distance $\mathrm{R} / \mathrm{D}=2$. But the tendency is maintained with nearly constant Nusselt number distribution at transition zone, $(1 \leq \mathrm{R} / \mathrm{D} \leq 2$ for $\mathrm{S} / \mathrm{D}=6$, and $1.4 \leq$ $\mathrm{R} / \mathrm{D} \leq 2.4$ for $\mathrm{S} / \mathrm{D}=8$ ), Fig. 7a and Fig. 8.

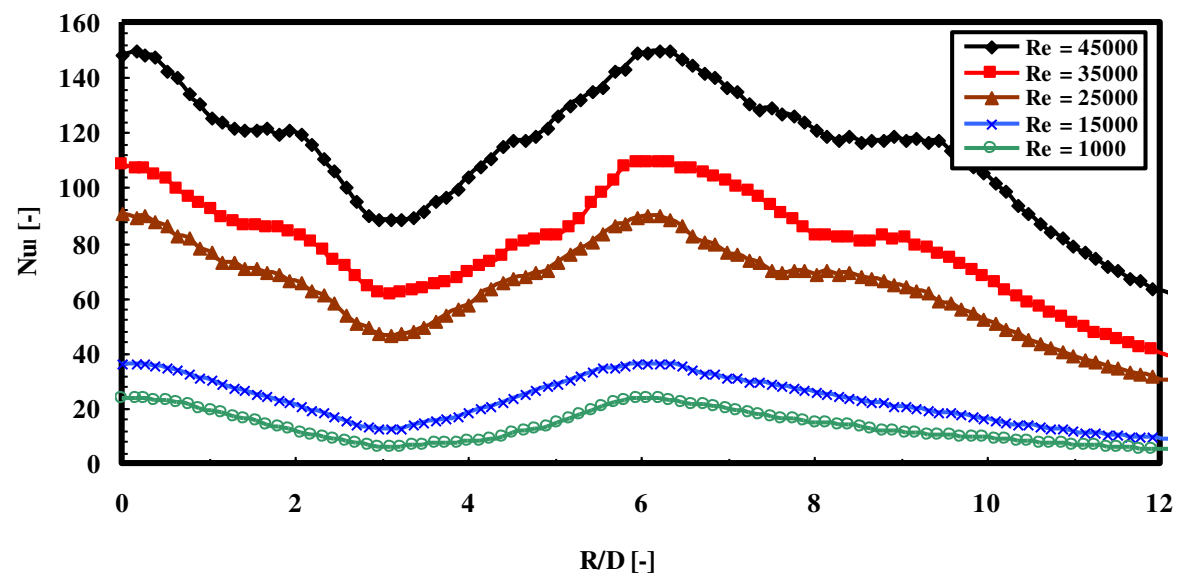

Fig. 7a. Radial variation of local Nusselt number at $S / D=6$, and $H / D=2.0$

Journal of Engineering Sciences, Assiut University, Faculty of Engineering, Vol. 41, No. 4, July, 2013,E-mail address: jes@aun.edu.eg 


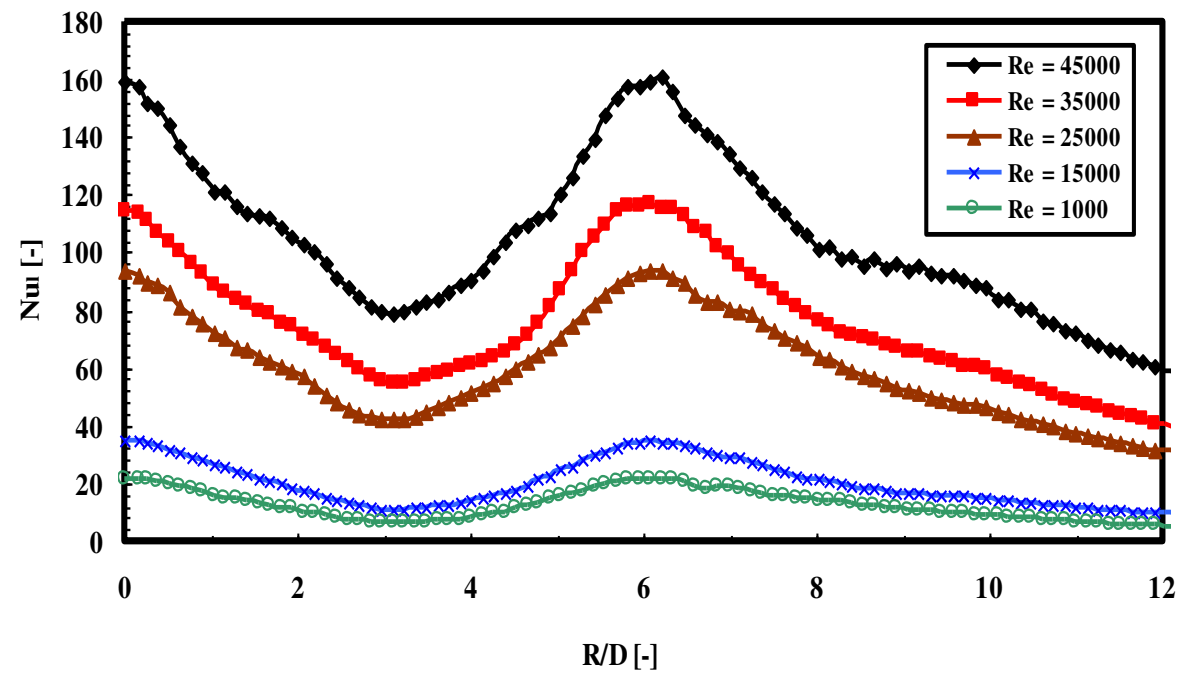

Fig. 7b. Radial variation of local Nusselt number at $S / D=6$, and $H / D=4.0$

Additionally, the magnitude of second peak increases by increasing Reynolds number. A similar result was observed by Aldabbagh and Mohamad [26] using 24 square jets (3 row X 8 columns) impinging on a moving heated plate with cross flow. This indicates that the jet to plate separation distance $\mathrm{H} / \mathrm{D} \leq 4$ can be a threshold for the second maximum to occur. After impinging on the flat plate, as the jet undergoes a boundary layer transition toward the wall jet region, its velocity is decaying at the same rate as going outward. Therefore, nearly the same amount of heat is transferred and the saturated flat shape can be seen in the transition zone between the stagnation region and the wall jet region. The saturation zone in the local Nusselt number distribution is gradually expanded in size and moves outward as the jet Reynolds number increases. This saturation zone in local Nusselt number may be related to the toroidal vortices being convicted to the impingement plate [26-27].

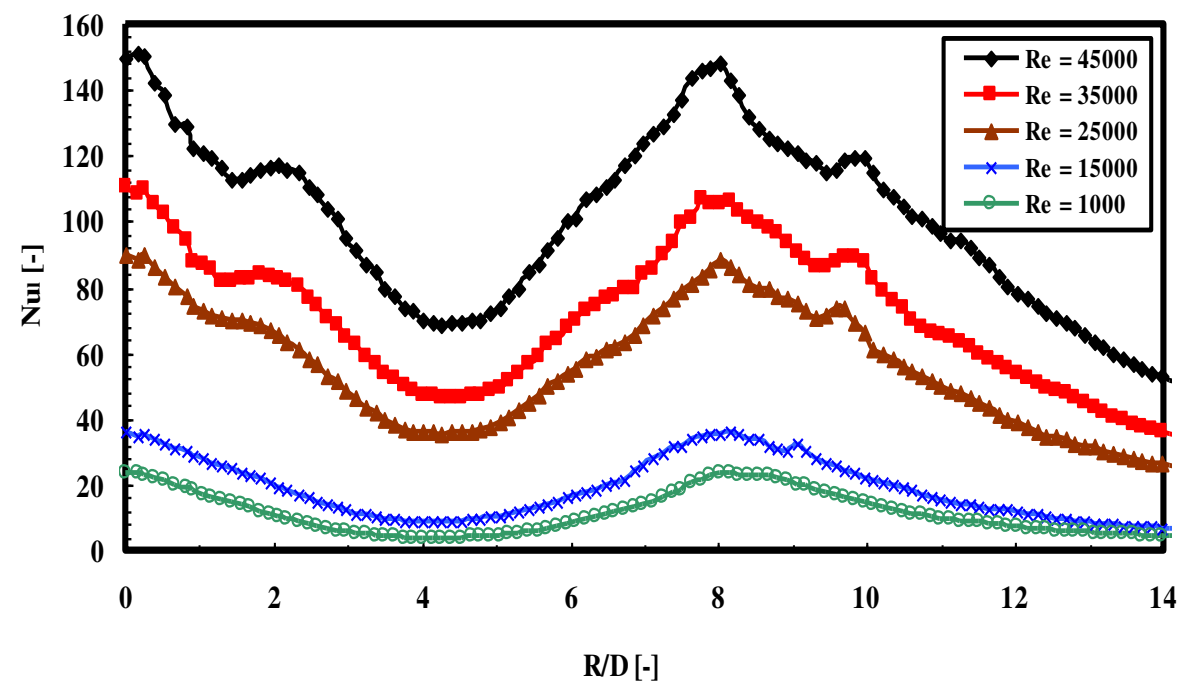

Fig. 8. Radial variation of local Nusselt number at $S / D=8$, and $H / D=2.0$

For jet to plate ratio $\mathrm{H} / \mathrm{D}=4$, these vortices and the large vortex structure appear to bear down into smaller scale turbulence that penetrates to the jet axis [26-27]. However, these

Journal of Engineering Sciences, Assiut University, Faculty of Engineering, Vol. 41, No. 4, July, 2013, E-mail address: jes@aun.edu.eg 
vortices do not penetrate core region for $\mathrm{H} / \mathrm{D} \leq 4[9,28]$. In case of the separation distance ratio increases to four, $\mathrm{H} / \mathrm{D}=4$, the peaks (first and second) are nearly disappearing because the turbulence intensity of the impinging has a local maximum at the first and stagnation points as shown in Fig. $7 \mathrm{~b}$.

In case of $S / D=8$, the profile of local Nusselt number is the same as that in single jet $[3,9]$ for separation distance $H / D=2$, Fig. 8 . For case of $H / D=2$, the first peak of local Nusselt number is at $\mathrm{R} / \mathrm{D}=0.25$ and the second peak at $\mathrm{R} / \mathrm{D}=2$.

\section{Average nusselt number}

The variation of the average Nusselt number, evaluated using Eq. (9), as a function of the separation distance and marked area as shown in Fig. 2, has been interpolated from the measurements for different spacing distances at three Reynolds number values and shown in Fig. 9. It is observed that, a value of H/D close to 2 seems indeed to correspond to a maximum average heat transfer independently of spacing distance S/D. This is partly due to the fact that the surface, over which the Nusselt number is averaged, is quite large in the stream wise direction which tends to smoothen the results. Heat transfer rate decreases as well when the impingement distance (separation distance) increases beyond $H / D>4$. At $H / D=8$, the impingement is too weak to cool the surface efficiently. As a rule of thumb, it would therefore be a good design practice to choose for a first attempt a separation distance $H / D=2[29,30]$.

Figure 10 shows the variation of average Nusselt number with spacing distance for three different Reynolds number values $(\operatorname{Re}=45000,25000$, and 1000). It is observed that the average Nusselt number at spacing distance $S / D=4$ is very close to the average Nusselt number for $S / D=2$ for all of the three values of Reynolds number. Consequently, the maximum average Nusselt number is obtained for $\mathrm{S} / \mathrm{D}=2$ within the range of distances tested. This result is not compatible with those results from Attala and Specht [4] that used nine jets $(3 * 3)$. They establish that the average Nusselt number is maximum at spacing distance $S / D=6$. This may be due to the weak interaction between flows coming out from jets when the spacing distance increased to 6 time the diameter.

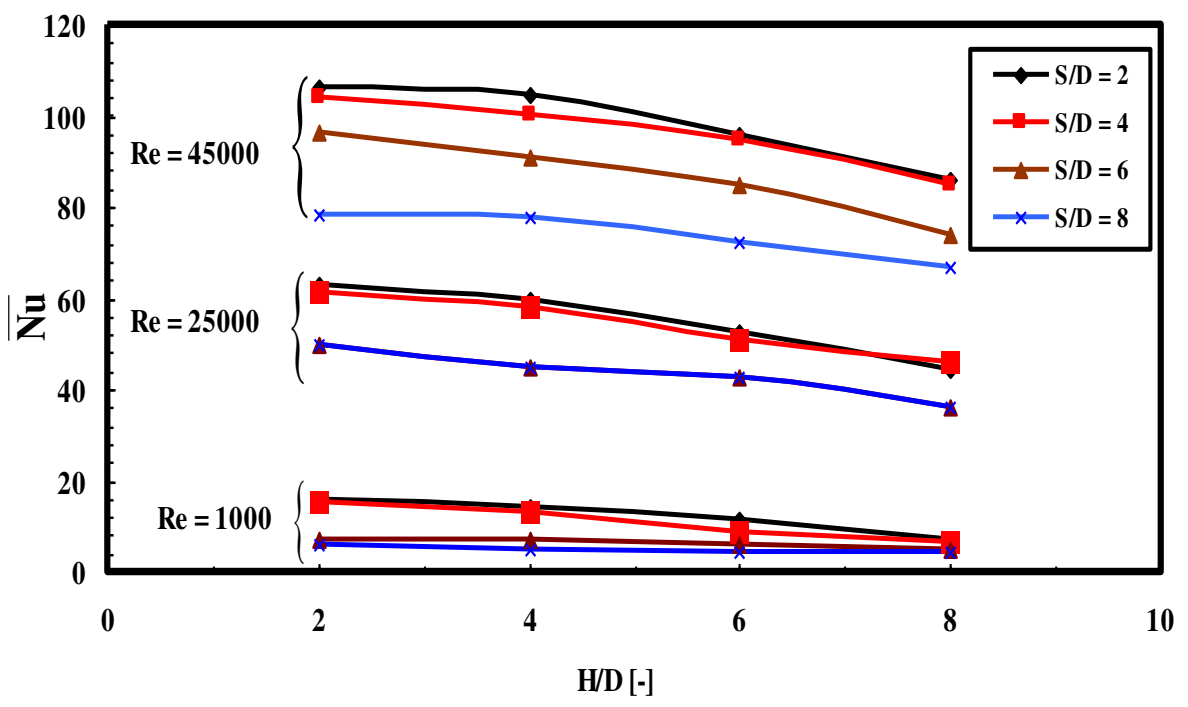

Fig. 9. Variation of average Nusselt number with separation distance at three different Reynolds number values.

In Fig. 10 one should not compare directly averaged Nusslet numbers for different separation distances H/D. Indeed the value of S/D governs directly the surface over which the averaged Nusselt number is calculated, Eq. (9). As an example averaged Nusslet

Journal of Engineering Sciences, Assiut University, Faculty of Engineering, Vol. 41, No. 4, July, 2013,E-mail address: jes@aun.edu.eg 
number for $S / D=2$ is higher than for $S / D=6$ but it does not mean that the cooling is more efficient for $S / D=2$, since the cooled surface taken into account is larger for $S / D=6$ than for $S / D=2$. To evaluate the overall cooling efficiency of the different impingement configurations and to be able to compare the different impingement cases, a fixed mass flow rate of cooling per unit area of cooled surface can be measured in different applications [30]. The aim of the designer is then to obtain maximum heat transfer rate with minimizing air quantity devoted for cooling of a given surface.

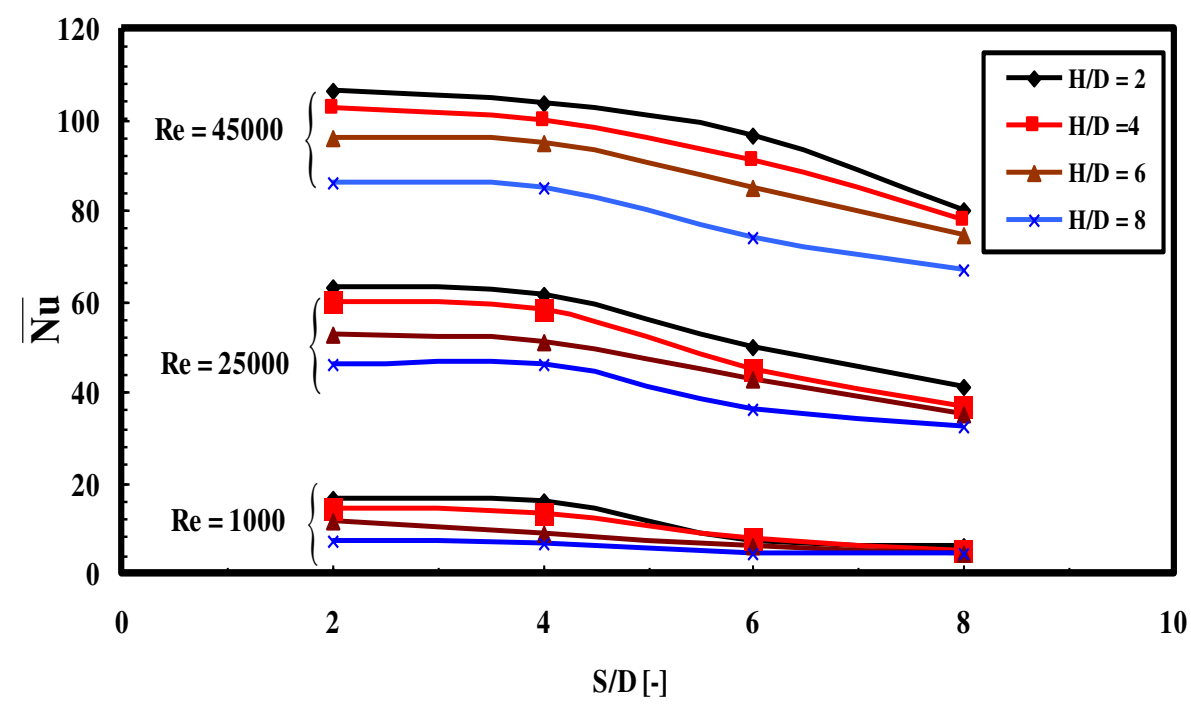

Fig. 10. Variation of average Nusselt number with spacing distances at three different Reynolds number values.

Figure 11 presents the average value of Nusselt number extracted from an area of one diameter $(\mathrm{R} / \mathrm{D}=1)$ which is comparable with the area of spacing distance $S / D=2$ as a function of Reynolds number. The average Nusselt number values were correlated to the one spacing distance, $\mathrm{S} / \mathrm{D}=2$, with $\mathrm{Re}$ and $\mathrm{H} / \mathrm{D}$ as independent variables. The correlation to the experimental data is

$$
\overline{\mathrm{Nu}}=0.105 * \operatorname{Re}^{0.68 *} \operatorname{Pr}^{0.33} *(\mathrm{H} / \mathrm{D})^{-0.103}
$$

The range of validity is the range of parameters for the experimental data which are $45000 \geq \operatorname{Re} \geq 1000,2 \geq \mathrm{H} / \mathrm{D} \geq 6$, and $\mathrm{S} / \mathrm{d}=2$.

The average Nusselt numbers reported in this study are compared to the correlation presented by Huber and Viskanta [10] in Fig. 11. It is observed that the heat transfer rate is enhanced by $6.3 \%$ in the array of five jets for spacing distance $S / D=2$ in comparison with the heat transfer of Huber and Viskanta [10]. The major difference between the average Nusselt number obtained by experimental data presented and that of [10] is attributed to the fact that the latter author used orifice made from perforated plates to produce their impinging air jets, while the results presented are based on data obtained from free jets.

Journal of Engineering Sciences, Assiut University, Faculty of Engineering, Vol. 41, No. 4, July, 2013,E-mail address: jes@aun.edu.eg 


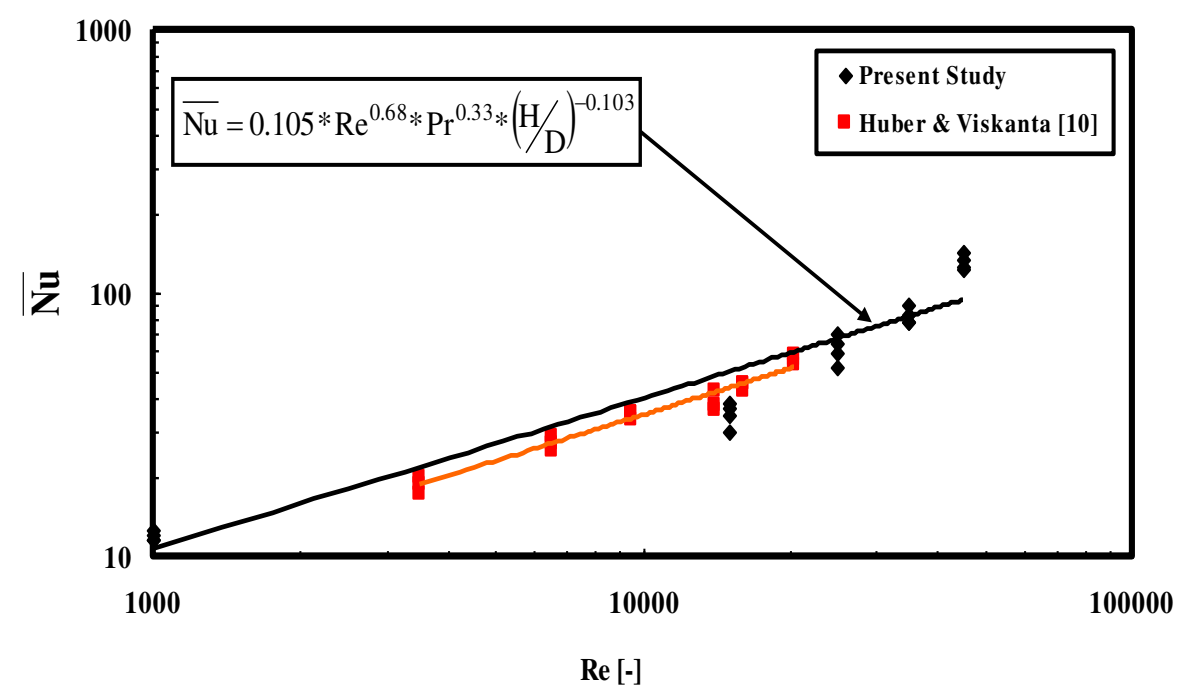

Fig. 11. Variation of average Nusselt number with jet Reynolds number, for $2 \leq H / D \leq 6$

\section{Conclusions}

The local heat transfer characteristics in a stagnation region were investigated experimentally of five circular free jets impinging into a heated flat plat. The temperature variations on the impinging surface were measured using a thermal infrared IR camera. For that reason, the heat transfer rate depends on the value of spacing distances, S/D. To sum up, it is concluded that;

1- The local Nusselt number distribution for the central jet has no second peak in stagnation region due to the interaction between flows which come out of the jets, for $\mathrm{S} / \mathrm{D}=2$, and $2 \geq \mathrm{H} / \mathrm{D} \geq 6$.

2- For larger spacing distances $S / D>6$, the local Nusselt number distribution of five jets has two peaks in stagnation region as the single jet.

3- The stagnation point Nusselt number was correlated for the jet Reynolds number as $\mathrm{Nu}_{\mathrm{st}} \propto \mathrm{Re}^{0.61}$.

4- The average Nusselt number is nearly the same as in the two locations $\mathrm{H} / \mathrm{D}=2$ and 4 in cases of spacing distances $2 \geq S / D \geq 8$, because the impingement plate is within the potential core length.

5- The average Nusselt number reached its maximum value at spacing distance of two diameter, $\mathrm{S} / \mathrm{D}=2$.

6- The average Nusselt number was correlated for the jet Reynolds number and the separation distance as $\overline{\mathrm{Nu}} \propto \mathrm{Re}^{0.68 *(\mathrm{H} / \mathrm{D})^{-0.103}}$.

\section{Acknowledgments}

These experimental results would not have been possible without the support of the staff of ISUT, Magdeburg, Germany.

Journal of Engineering Sciences, Assiut University, Faculty of Engineering, Vol. 41, No. 4, July, 2013,E-mail address: jes@aun.edu.eg 


\section{Nomenclature}

$\begin{array}{ll}\text { A } & \text { Plate area }\left(\mathrm{m}^{2}\right) \\ \mathrm{D} & \text { Inner nozzle diameter (m) } \\ \mathrm{H} & \text { Distance from jet exit to impingement plate (m) } \\ \mathrm{I} & \text { Direct current (A) } \\ \mathrm{k} & \text { Thermal conductivity of air (W/m.K) } \\ \mathrm{k}_{\mathrm{m}} & \text { Thermal conductivity of metal sheet (W/m.K) } \\ \mathrm{Nu} & \text { Local Nusselt number (-) } \\ \overline{\mathrm{Nu}} & \text { Average Nusselt number (-) }\end{array}$

$\mathrm{q}_{\mathrm{k}} \quad$ Conduction net heat transfer rate in radial direction for an element per unit surface area $\left(\mathrm{W} / \mathrm{m}^{2}\right)$

$\begin{array}{ll}\mathrm{q}_{\mathrm{I}} & \text { Electrical power per unit area }\left(\mathrm{W} / \mathrm{m}^{2}\right) \\ \mathrm{q}_{\mathrm{R}} & \text { Radiation heat per unit area }\left(\mathrm{W} / \mathrm{m}^{2}\right) \\ \mathrm{q}_{\alpha} & \text { Convective heat per unit area }\left(\mathrm{W} / \mathrm{m}^{2}\right) \\ \mathrm{q}_{\alpha \mathrm{f}} & \text { Convection heat flux of lower surface of sheet }\left(\mathrm{W} / \mathrm{m}^{2}\right) \\ \mathrm{Re} & \text { Jet Reynolds number }(-) \\ \mathrm{R} & \text { Radius from the centre of the central jet }(\mathrm{m}) \\ \mathrm{S} & \text { Jet-to-jet spacing distance }(\mathrm{m}) \\ \mathrm{T}_{\mathrm{a}} & \text { Ambient temperature }\left({ }^{\circ} \mathrm{C}\right) \\ \mathrm{T}_{\mathrm{ad}} & \text { Adiabatic metal sheet temperature }\left({ }^{\circ} \mathrm{C}\right) \\ \mathrm{T}_{\mathrm{o}} & \text { Heated metal sheet temperature }\left({ }^{\circ} \mathrm{C}\right) \\ \mathrm{T}_{\mathrm{j}} & \text { Jet exit temperature }\left({ }^{\circ} \mathrm{C}\right) \\ \overline{\Delta \mathrm{T}} & \text { Average temperature differences }(\mathrm{C}) \\ \mathrm{t} & \text { Metal sheet thickness }(\mathrm{m}) \\ \mathrm{V} & \text { Mean velocity at jet exit }(\mathrm{m} / \mathrm{s}) \\ \mathrm{W} & \text { Metal sheet width }(\mathrm{m}) \\ \frac{\text { Greek symbols }}{\alpha} & \text { Convective heat transfer coefficient }\left(\mathrm{W} / \mathrm{m}^{2} . \mathrm{K}\right) \\ \nu & \text { Kinematic viscosity }\left(\mathrm{m}^{2} / \mathrm{s}\right) \\ \rho_{\mathrm{el}} & \text { Specific electric resistance }(\Omega \mathrm{m}) \\ \sigma & \text { Stefan-Boltzmann constant }\left(\mathrm{W} / \mathrm{m}^{2} . \mathrm{K}^{4}\right) \\ \underline{\text { Subscripts }} & \\ \mathrm{f} & \text { Free convective } \\ \mathrm{l} & \text { Local value } \\ \text { st } & \text { Stagnation point }\end{array}$

\section{References}

[1] Martin H. (1977), Heat and Mass Transfer between Impinging Gas Jets and Solid Surface. Adv. Heat Mass Transfer, 13:1-60.

[2] Viskanta R. (1993), Heat Transfer to Impinging Isothermal Gas and Flame Jets. Exp Thermal and Fluid Flow Sci, 6:111-134.

[3] Xiaojun Yan and Nader Saniei (1996) Measurements of Local Heat Transfer Coefficients from a Flat Plate to a Pair of Circular Air Impinging Jets. Exp Heat Transfer, 9:29-47.

Journal of Engineering Sciences, Assiut University, Faculty of Engineering, Vol. 41, No. 4, July, 2013,E-mail address: jes@aun.edu.eg 
[4] Attalla M. and Specht E. (2009), Heat Transfer Characteristics from In-Line Arrays of Free Impinging Jets. J. Heat and Mass Transfer, 45:537-543.

[5] Popiel C. O. and Boguslawski L. (1988), Effect of Flow Structure on the Heat or Mass Transfer on a Flat Plate in Impinging Round Jet. Proc. 2nd Uk Natl. Conf. on Heat Transfer, University of Strathclyde, UK 1:663-685.

[6] Boguslawski L. and Popiel C. O. (1979), Flow Structure of the Free Round Turbulent Jet in the Initial Region. Int. J Fluid Mech., 90:531-539.

[7] Brahma R. K. and Kharagpur India (1992), Prediction of Stagnation Point Heat Transfer for a Slot Jet Impinging on a Flat Surface. Warm und Stoffubertragung, 27:61-66.

[8] Everitt K. W. and Robins A. G. (1978), The Development and Structure of turbulent Plane Jets. Int. J. of Fluid Mech., 88 Part 3:563-583.

[9] Lee J. and Sang-Joon Lee (1999), Stagnation Region Heat Transfer of a Turbulent Axisymmetric Jet Impingement. Exp. J. Heat Transfer, 12:137-156.

[10] Huber A. M. and Viskanta R. (1994), Effect of Jet-to-Jet Spacing on Convective Heat transfer to Confined Impinging Arrays of Aixsymmetric Air Jets Int. J. of Heat and Mass transfer, 37:2859-2869.

[11] Koopman R. N. and Sparrow E. M. (1976), Local and Average Heat Transfer Coefficient Due to an Impinging Row of Jets. Int. J. of Heat and Mass Transfer, 19: 673-683.

[12] Hollworth B. R. and Berry R. D. (1978), Heat Transfer from Arrays of Impinging Jets with Large Jet-to-Jet Spacing. Int. J. of Heat Transfer, 100:352-357.

[13] Goldstein R. J. and Timmer J. F. (1982), Visualization of Heat Transfer from Arrays of Impinging Jets. Int. J. of Heat and Mass Transfer, 111:1096-1098.

[14] Goldstein R. J. and Behbahn A. J. (1982), Impingement of a Circular Jet with and without Crossflow. Int. J. of Heat and Mass Transfer, 25: 1377-1383.

[15] Gardon R. and Akfirat J. C. (1965), The Role of Turbulent in Determining the Heat Transfer Characteristics of Impinging Jets. Int. J. of Heat and Mass Transfer, 8:597-605.

[16] Hoogendoorn C. J. (1977), The Effect of Turbulence on Heat Transfer at a Stagnation Point. Int. J. of Heat and Mass Transfer, 20:1333-1338

[17] Katoka K. (1990), Impingement Heat Transfer Augmentation due To Large Scale Eddies. Proc. 9th Int. Heat Transfer Conf., Hemisphere, Washington, DC 1:255-273.

[18] Obat N. T., and Majumdar A. S. and Douglas W. S. (1979), The Effect of Nozzle Geometry on Impingement Heat Transfer Under Round Turbulent Jet. ASME Paper WA/HT-53, ASME New York.

[19] Aldabbagh L. B. Y. and Mohamad A. A. (2007), Effect of Jet-to-Plate Spacing in Laminar Array Jets Impinging. J. Heat and Mass Transfer, 43:265-273.

[20] Puschmann F., Specht E. and Schmid J. (2001), Measurement of Spray cooling Heat Transfer Using an Infrared-Technique in Combination with the Phase-Doppler Technique and a Paternoster. Int. J. Heat and Technology, 19:51-56.

[21] Attalla M. (2005), Experimental Investigation of Heat transfer Characteristics from Array of Free Impinging Circular Jets and Hole Channels. PhD Otto von-Guericke University, Magdeburg, Germany.

[22] Buchlin J. M., Brossard J. and Gouriet J. B. (2004), Infrared Thermograph Study of Heat Transfer in an Array of Round Jets. 7th Int Conf. on Quantitative Infrared Thermograph, Von Karman Institute of Fluid Dynamics, Rhode Saint Genese, Belgium:5-8.

[23] Kline S. J. and McClintock F. A. (1953), Describing Uncertainties in Single Sample Experiments. Mech. Engineering, 75:3-8.

[24] Jung-Yang San and Mao-De Lai (1994), Optimum Jet-to-Jet Spacing of Heat Transfer for Staggered Arrays of impinging Air Jets. Int. J. of Heat and Mass Transfer, 37:3997-4007.

[25] Gardon R. and Cobonpus J. (1962), Heat Transfer Between a Flat Plate and Jets of Air Impinging on It. proc. 2nd Int. Heat Transfer Conf., ASME, New York:454-460.

Journal of Engineering Sciences, Assiut University, Faculty of Engineering, Vol. 41, No. 4, July, 2013,E-mail address: jes@aun.edu.eg 
[26] Aldabbagh L. B. Y. and Mohamad A. A. (2009), A Three Dimensional Numerical Simulations of Impinging Jet Arrays on a Moving Plate. Int. J. of Heat and Mass Transfer, 52:4894-4900.

[27] Aldabbagh L. B. Y., Sezai I. and Mohamad A. A, (2003), Three Dimensional Investigation of a Laminar Impinging Square Jet Interaction with Cross-Flow. J. Heat Transfer, 125:243-249.

[28] Lee J. and Sang-Joon Lee (2000), The Effect of Nozzle Aspect Ratio on Stagnation Region Heat Transfer Characteristic of Elliptic Impinging Jet. Int. J. of Heat and Mass Transfer, 43:555-575.

[29] Jambunathan K., Lai E, Moss M. A. and Button B. L. (1992) A Review of Heat Transfer Data for Single Circular Jet Impinging Isothermal Gas and Flame Jets. Int. J. of Heat Fluid Flow, 13:106-115.

[30] Berevet P., Dejeu C., Dorignac E., Jolly M. and Vullierme J. J. (2002), Heat Transfer to a Row of Impinging Jets in Consideration of Optimization. Int. J. of Heat and Mass Transfer, 45:4191-4200.

\section{انتقال حرارة نقطة الركود النتاج من تصادم نفاثات هوائية دائرية مضطربة}

\section{الملخص العربى}

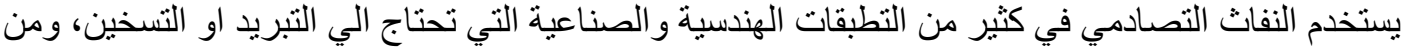

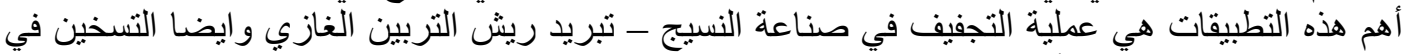

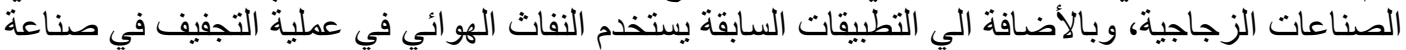

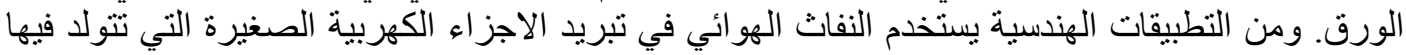

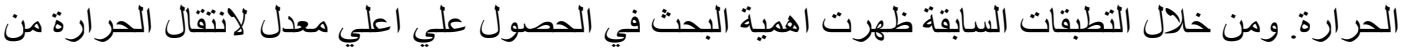

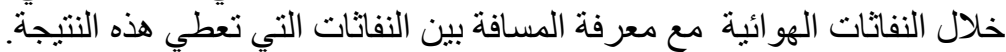

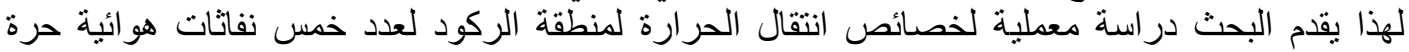

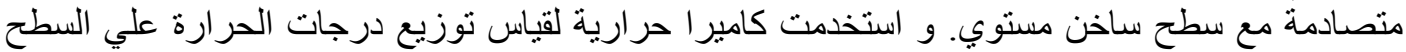

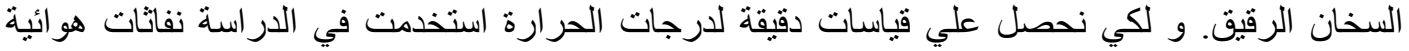

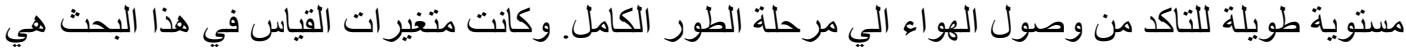

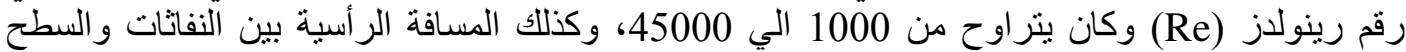

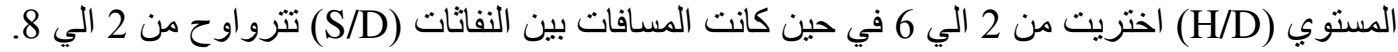
وكان نرثيب النفاثات الهوائية عبارة عن نفاث في الوسط وحولة اربعة نفاثات علي ابعاد منساوية من بعضئ البعض. ومن اهم النتائج التي توصلت إليها الدراسة هي ان رقم ناسيلت (Nu) في منطقة الركود يتناسب مع رقم رينولدز (Re) طبقا للمعادلة التالية

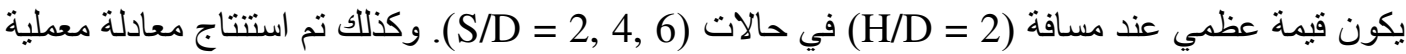

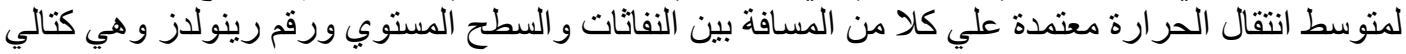

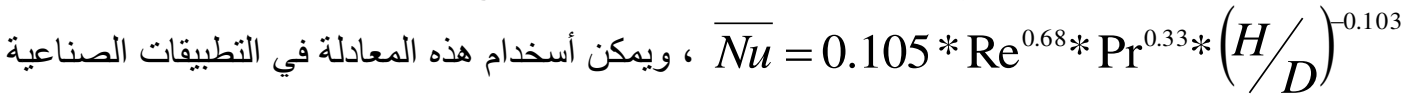
المختلفة للحصول علي نسبة التبريد المطلوبة بمعرفة المسافة بين النفاث والسطح المستوي وكمية الهواء المندفع خلالة 